www.jmscr.igmpublication.org

Impact Factor 5.84

Index Copernicus Value: 83.27

ISSN (e)-2347-176x ISSN (p) 2455-0450

crossref DOI: https://dx.doi.org/10.18535/jmscr/v5i1.122

Journal Of Medical Science And Clinical Research

IGM Publication

An Official Publication of IGM Publication

\title{
A Retrospective Study on Risk Factors and Clinical Presentation of Ectopic Pregnancy
}

\author{
Authors \\ P. Sujata ${ }^{1}$, Janmejaya Sahoo ${ }^{2}$, Jagadish Hansa ${ }^{3}$ Gangadhar Sahoo $^{4}$ \\ ${ }^{1,4}$ Department of Obstetrics and Gynaecology, IMS and SUM Hospital, Bhubaneswar-751003, Odisha, India \\ ${ }^{2}$ Department of Anaesthesiology, IMS and SUM Hospital, Bhubaneswar-751003, Odisha, India \\ ${ }^{3}$ Post-doctoral fellow, Directorate of Medical Research \& Life Sciences, IMS and SUM Hospital, \\ Bhubaneswar-751003, Odisha, India \\ Corresponding Author \\ Dr. P. Sujata \\ Associate Professor, Dept. Of O\&G, IMS \&SUM Hospital, Bhubaneswar. \\ Email:psujata123@gmail.com
}

\begin{abstract}
Introduction: The objectives are to study the incidence, clinical presentations and risk factors of all cases of ectopic pregnancy that presented to our centre over a period of five years.

Method: A retrospective study was done on all cases of ectopic pregnancies who were admitted to the $O \& G$ dept. of Institute of Medical Sciences and SUM Hospital, under Siksha 'O' Anusandhan University, Bhubaneswar from January 2009 to December 2013. Information was obtained from the case notes, theatre and labour ward registers.
\end{abstract}

Results and Discussion: A total of 200 cases of ectopic pregnancy were diagnosed. The total no. of deliveries which took place during the study periods were 6084. The incidence of ectopic pregnancy in the present study was 3.2\%. Risk factors were present in 35\% of cases. Majority of the cases were ampullary pregnancies (66.5\%). Ectopic pregnancy presented with diverse symptoms. Majority of the cases (39\%) presented with pain abdomen. Abdominal pain is due to peritoneal irritation as most of the cases had rupture ectopics at the time of presentation. Death occurred in 3 cases which were mainly due to delay in referral.

Conclusion: The incidence of ectopic pregnancy in our centre was 3.2\%. The most common identifiable risk factor was PID.

Keywords: PID, Ampulla, infertility, abortion, ectopic.

\section{Introduction}

Ectopic pregnancy is still one of the main causes of maternal mortality and morbidity ${ }^{[1]}$. Recognition of high risk cases, early diagnosis with the use of transvaginal sonography, serum beta-HCG, and laparoscopy have significantly improved the management of ectopic pregnancy. Any sexually active woman presenting with abdominal pain and vaginal bleeding after an interval of amenorrhoea should be provisionally diagnosed as an ectopic pregnancy until proved otherwise. The incidence of ectopic pregnancy has quadrupled in the past two decades ${ }^{[2]}$. Several risk factors like tubal sterilisation, previous ectopic pregnancy, intrauterine devices, infertility, PID and prior abortions are some of the causative 
factors in the development of ectopic pregnancy. The rise in incidence of ectopic pregnancy is multi factorial: Change in life style \& sexual behaviour; increased incidence of PID due to polygamy \& Polyandry; increase in facility for diagnosis; increase in health education awareness etc. This study was carried out to know the risk factors and clinical presentations associated with ectopic pregnancy to comprehend the treatment modalities.

\section{Material and Methods}

This is a retrospective study on all the cases of ectopic pregnancy who were admitted to the Obstetrics and Gynaecology department of institute of Medical Sciences and SUM hospital, Bhubaneswar, Odisha, covering the period from January 2009 to December 2013. Each record was scrutinized for age, parity and marital status. The other information extracted included risk factors, clinical presentations, intraoperative findings and outcome of ectopic pregnancies. A total of 200 cases of ectopic pregnancy were diagnosed. The total number of deliveries which took place during the study period were 6084 .

\section{Results}

This study was undertaken in the department of Obst. \& Gynaec. of Institute of Medical Sciences and SUM hospital, Bhubaneswar, Odisha from January 2009 to December 2013. The incidence of ectopic pregnancy in the present study is $3.2 \%$. A majority of the cases (34\%) were in the age group 26-30 years [Table-1].

As regards to parity $60 \%$ cases were in the group $\mathrm{P} 0-\mathrm{P} 1,39.5 \%$ were $\mathrm{P} 2-\mathrm{P} 3$ and one case was $\geq \mathrm{P} 4$. Most of the cases were married at the time of presentation (97.5\%) [Table1]. Risk factors were present in only $35 \%$ of cases. The common risk factor was PID. $7.5 \%$ cases had ectopic pregnancy following treatment for infertility. Three cases had previous ectopic pregnancies. Sterilization reversal was observed in $3.5 \%$ cases and in 5\% cases tubal ligation had been done. One case had Koch's abdomen [Table 2].
A majority of the cases were ampullary pregnancies $(66.5 \%) .11 \%$ cases were in the isthmus. Tubal abortion was seen in $5 \%$ cases. There was one case of ovarian pregnancy and one case of heterotrophic pregnancy.49\% had left sided ectopic pregnancy and $47.5 \%$ had right sided ectopic pregnancy [Table 3].

Majority of the patients presented with pain in the abdomen (39\%). $20 \%$ cases were in a state of shock at the time of admission. Two cases of chronic ectopic presented with retention of urine [Table 4].

Tenderness on cervical movement was present in $75 \%$ cases. Ultrasound revealed a ruptured ectopic pregnancy in $67.5 \%$ cases, an unruptured ectopic pregnancy in $5 \%$ cases, and an adnexal mass in $25 \%$ cases [Table 5].

The postoperative period was uneventful in majority of the cases. Three cases resulted in death. Ten cases needed ICU admissions [Table 6]. Cervical and abdominal pregnancies were not observed in the present study.

Table - 1 Socio - Demographic Profile

\begin{tabular}{|l|c|c|}
\hline Age Distribution & Number & Percentage (\%) \\
\hline$<25$ years & 55 & 27.5 \\
\hline 26-30 years & 68 & 34 \\
\hline 31-35 years & 42 & 21 \\
\hline 36-40 years & 35 & 17.5 \\
\hline Parity & & \\
\hline P0 - P1 & 120 & 60 \\
\hline P2 - P3 & 79 & 39.5 \\
\hline$\geq$ P4 & 1 & 0.5 \\
\hline Marital Status & & \\
\hline Married & 195 & 97.5 \\
\hline Un Married & 5 & 2.5 \\
\hline
\end{tabular}

Table - 2 Risk Factors

\begin{tabular}{|l|c|c|}
\hline RISK FACTORS & Number & Percentage (\%) \\
\hline PID & 22 & 11 \\
\hline Previous abortions & 10 & 5 \\
\hline $\begin{array}{l}\text { Previous ectopic } \\
\text { pregnancy }\end{array}$ & 3 & 1.5 \\
\hline $\begin{array}{l}\text { Infertility } \\
\text { treatment }\end{array}$ & 15 & 7.5 \\
\hline Koch's abdomen & 1 & 0.5 \\
\hline IUCD use & 1 & 0.5 \\
\hline OCPill use & 1 & 0.5 \\
\hline Tubal ligation & 10 & 5 \\
\hline $\begin{array}{l}\text { Sterilization } \\
\text { reversal }\end{array}$ & 7 & 3.5 \\
\hline
\end{tabular}


Table - 3 Site of Ectopic Pregnancy

\begin{tabular}{|l|c|c|}
\hline $\begin{array}{l}\text { SITE OF ECTOPIC } \\
\text { PREGNANCY }\end{array}$ & Number & Percentage (\%) \\
\hline Ampulla & 133 & 66.5 \\
\hline Fimbria & 13 & 6.5 \\
\hline Isthmus & 22 & 11 \\
\hline Cornual & 19 & 9.5 \\
\hline Tubal abortion & 5 & 5 \\
\hline Ovary & 1 & 0.5 \\
\hline Heterotrophic & 1 & 0.5 \\
\hline $\begin{array}{l}\text { SIDE OF ECTOPIC } \\
\text { PREGNANCY }\end{array}$ & & \\
\hline Right Side & 95 & 47.5 \\
\hline Left Side & 98 & 49 \\
\hline
\end{tabular}

Table - 4 Symptoms In Patients With Ectopic Pregnancy

\begin{tabular}{|l|c|c|}
\hline $\begin{array}{l}\text { Presenting } \\
\text { Complaints }\end{array}$ & Number & Percentage (\%) \\
\hline Abdominal Pain & 108 & 54 \\
\hline $\begin{array}{l}\text { Abnormal Vaginal } \\
\text { Bleeding }\end{array}$ & 50 & 25 \\
\hline Shock & 40 & 20 \\
\hline Retention of Urine & 2 & 1 \\
\hline
\end{tabular}

Table - 5 Type of Ectopic Pregnancy (Usg \& Intra-Operative Findings)

\begin{tabular}{|l|c|c|}
\hline & Number & Percentage (\%) \\
\hline Ruptured & 135 & 67.5 \\
\hline Unruptured & 10 & 5 \\
\hline Chronic & 50 & 25 \\
\hline Tubal abortion & 5 & 2.5 \\
\hline
\end{tabular}

Table - 6 Complications

\begin{tabular}{|l|c|c|}
\hline COMPLICATIONS & Number & Percentage (\%) \\
\hline Severe Anaemia & 70 & 35 \\
\hline Shock & 40 & 20 \\
\hline Death & 3 & 1.5 \\
\hline ICU Admission & 10 & 5 \\
\hline
\end{tabular}

\section{Discussion}

Ectopic pregnancy still contributes significantly to the cause of maternal mortality and morbidity. The incidence of ectopic pregnancy in our study was $3.2 \%$. The incidence in this study is higher as compared to other studies. The increased incidence in our study may be due to its tertiary status. Also the high incidence of suspicion and better diagnostic facilities may be contributory. The incidence of ectopic pregnancy varies from country to country. There is currently an increase in the incidence of ectopic pregnancy globally. The incidence varies from 1 in 300 to 1 in 150 deliveries ${ }^{[1]}$. The increase in the incidence of ectopic pregnancy is associated with advances in assisted reproductive technology, tubal surgeries and female operative sterilization and earlier diagnosis with more sensitive methods of cases that otherwise could have resolved without causing any symptoms [Arup et al, 2007].

There were more number of cases in the age group 26-30 years. Our findings were similar to the findings of Igwegbe et al ${ }^{[2]}$. The possible reason for this finding is that in recent years, the age at first conception has increased, which ultimately contributes to the increased incidence ${ }^{[3]}$. Age has long been suspected to play a role in ectopic pregnancy risk, but studies have provided conflicting results ${ }^{[4]}$. In a study by Bouyer et al $34 \%$ cases were in the age group 30-34yrs ${ }^{[4]}$. There was a significant difference in the findings between our study and the findings of a study by Bouyer et al ${ }^{[4]}$. Al-Turki et al ${ }^{[5]}$ also showed that majority of the patients $(61.1 \%)$ were below the age of 30 yrs. Hamura et al ${ }^{[6]}$ showed a majority of the cases $(95 \%)$ were aged $>25$ yrs. $60 \%$ cases in our study are either nulliparous or Primi parous. The rest $40 \%$ were multiparous. The prevalence of ectopic pregnancy is mostly related to nulli parity ${ }^{[1]}$. A study by Gaddagi et al ${ }^{[7]}$ concluded that $27 \%$ cases were nulliparous, $10.8 \%$ were primiparous and $62.2 \%$ were multiparous .Hamura et al ${ }^{[6]}$ found that $15 \%$ women were nulliparous, $56 \%$ were Para one or para two. In a study by Igwegbe et al ${ }^{[2]}$ multiparous patients were the largest $(54.8 \%)$. These findings were quite different from that of our study. The gestational age at presentation could not be known since documentation of data was insufficient. Most of the women were married $(97.5 \%)$. A study by Hamura et al ${ }^{[6]}$ also showed an almost similar figure (93\%).

Risk factors were found in only $35 \%$ cases. The commonest risk factor was PID. $11 \%$ cases had macroscopic evidence of PID at surgery. A study by Gaddagi et al ${ }^{[7]}$ had almost similar result in 
which $8.1 \%$ cases of ectopic pregnancy were due to PID. Our findings were different from the findings of Hamura et al ${ }^{[6]}$ in which $43 \%$ cases had macroscopic evidence of PID at the time of surgery. The importance of infectious factors in ectopic pregnancy is well documented. Salpingitis and pelvic inflammatory disease increase the risk of ectopic pregnancy 6-10 fold ${ }^{[1]}$. It is likely that PID represents an important risk factor for tubal ectopic pregnancy in observations made by certain authors. In other studies ${ }^{[8,9]}$ Igwegbe et al ${ }^{[2]}$ showed previous induced abortions (37\%) were the commonest risk factor, followed by pelvic infections $(35.5 \%)$. But in our study only 5\% cases had previous abortions. There are conflicting reports regarding the role which induced abortions play in the risk of ectopic pregnancy. The results concerning prior spontaneous abortions differ among studies. Spontaneous abortions may have a casual effect possibly mediated by infection. Holt et al [10] reported that induced abortions does not increase the risk of ectopic pregnancy .Prior induced abortions significantly increase the risk of ectopic pregnancy ${ }^{[1]}$. Three cases $(1.5 \%)$ in our study had previous ectopic pregnancies. In a study by Gaddagi et al ${ }^{[7]}, 2.7 \%$ cases had previous ectopic pregnancy and in a study by Roseet al (2002), the incidence was $3.2 \%$ which is almost similar to our study. There are $10-15 \%$ chances of repeat ectopic pregnancy ${ }^{[1]}$. This is because tubal disease is nearly always bilateral and because there is a strong tendency for ectopic pregnancy to occur first on one side and later on the other side ${ }^{[11]}$. $7.5 \%$ cases of ectopic pregnancy occurred following infertility treatment. The incidence of ectopic pregnancy following infertility treatment is much higher as compared to spontaneous pregnancies. The association between infertility and ectopic pregnancy is complex as it can be a consequence of infertility as well as a cause. One case had ectopic pregnancy with IUD in situ. IUD prevents intrauterine pregnancy effectively but tubal implantation to a lesser extent .There is a relative increase in tubal pregnancies (7 times more) should pregnancy occur with IUD in situ ${ }^{[1]}$. Tubal surgeries (tubal ligation and sterilization reversal) accounted for $8.5 \%$ cases. There is 15 $50 \%$ chance of being ectopic if pregnancy occurs following tubal surgeries ${ }^{[1]}$. The risk of ectopic pregnancy after sterilization is greatest when laparoscopicelectro destruction and partial salpingectomy are carried out ${ }^{[12]}$. Among 10,685 women studied, the risk of ectopic pregnancy within 10 yrs. after sterilisation was about 7 per 1000 procedures ${ }^{[12]}$.

The tubes remained the commonest site of ectopic pregnancy in our review, the ampulla being commonly affected. Between 93 and $98 \%$ of ectopic pregnancies are located in the fallopian tube. Of these in turn $75 \%$ are located in the ampulla, $13 \%$ in the isthmus and $12 \%$ in the fimbriae. Ampulla was involved in $66.5 \%$ of cases in our study. This is similar to the findings of a study by Igwegbe et al ${ }^{[2]}$ in which ampulla was the most commonly affected site of the tube. In studies by Gaddagi et al ${ }^{[7]}$, Chow et al (1987) and Rose et al (2002), ampulla was also the most common site of ectopic pregnancy. There was one case of ovarian pregnancy in this study which was ruptured at the time of presentation. Ovarian pregnancies are rare. Only about $0.15 \%-3 \%$ of ectopics occur in the ovary ${ }^{[13]}$. Ovarian pregnancy accounts for $20-30 \%$ of all ectopics in IUCD users. There was one case of heterotrophic pregnancy in the present study. Only a few cases of heterotrophic pregnancies are reported (Aliyur et al, 2008, Pratt et al 1988). The once extremely rare condition of heterotrophic pregnancy is now more common with the advent of in-vitro fertiliser and embryo transfer. The incidence is about 1 in 8000 pregnancies at present ${ }^{[1]}$. There was no case of abdominal or cervical pregnancy in our study.

Abdominal pain was the most common presenting symptom in our study (54\%). Abdominal pain was the most common presenting symptom in a study by Igwegbe et al ${ }^{[2]}$. These findings are similar to the findings of other studies ${ }^{[14]}$. Abdominal pain is due to peritoneal irritation and is not unusual since most of the patients presented with ruptured 
ectopic. The pain could also be caused by tubal miscarriage and bleeding through the fimbrial end of the tube into the peritoneal cavity ${ }^{[15]}$. Ectopic pregnancy could present with diverse symptoms as shown in this study. Vaginal bleeding was observed in $25 \%$ cases. Orji et al ${ }^{[16]}$ in a study have shown that about $10-20 \%$ of ectopic pregnancies may present without vaginal bleeding. There are no specific symptoms or signs that are pathognomonic of ectopic pregnancy. The absence of vaginal bleeding contributes to the late presentation and the consequent rupture ectopic pregnancy. Vaginal bleeding was observed in $35.8 \%$ of patients with ectopic pregnancy in a study by Igwegbe et al ${ }^{[2]}$. $43.2 \%$ of cases presented with vaginal bleeding in a study by Gadaggi et al ${ }^{[7]}$. $20 \%$ cases were in a state of shock at the time of presentation. Gaddagi et al ${ }^{[7]}$ reported $40.5 \%$ cases in a state of shock. In a study by Hamura et al ${ }^{[(6]} 1 / 3 \mathrm{rd}$ of the women had shock on arrival. Two cases of chronic ectopic presented with retention of urine in our study.

Ectopic pregnancies were ruptured in $67.5 \%$ cases seen at presentation. These findings are almost similar to the findings of a study by Igwegbe et al ${ }^{[2]}$ in which majority of the cases $(80.6 \%)$ were ruptured ectopics. The findings in this study are also similar to the findings by Gaddaggi et al ${ }^{[7]}$ in which $78.3 \%$ cases were ruptured ectopics at the time of presentation.

The post-operative period was uneventful in a majority of the cases. Ten cases required ICU admissions for various reasons. Death occurred in three cases $(1.5 \%)$. All the three cases were referred ones. They were already in a state of shock on arrival at the hospital. Delay in referral was the main cause of death in these patients. The maternal mortality rate as published by numerous hospital based studies lie between $1 \%$ and $3 \%$ of all cases of ectopic pregnancy ${ }^{[2]}$. Early diagnosis before rupture is important in reducing mortality as well as preserving the potential for future fertility through conservative management ${ }^{[23]}$.

\section{Conclusion}

The incidence of ectopic pregnancy in our centre was $3.2 \%$.This increased incidence may be due to its tertiary status. All the cases were diagnosed with a high index of clinical suspicion and the USG findings corroborated to the diagnosis. The most common identifiable risk factor was pelvic inflammatory disease. Efforts should be directed at prevention and adequate treatment of PID and sexually transmitted infections. Early diagnosis before tubal rupture is important in reducing the morbidity and mortality associated with ruptured ectopic pregnancy. In vulnerable population the clinician should be "ectopic minded" for early diagnosis. According to authors' view over diagnosis of ectopic pregnancy is a reality but under diagnosis is a crime.

\section{Conflict of Interest: None}

\section{References}

1. Dutta DC. Haemorrhage in Early pregnancy. In: Koner H, editor. Textbook of Obstetrics. Revised reprint of $7^{\text {th }}$ edition: Nov. 2013. Pg 177- pg. 190

2. Igwegbe AO, Eleje Gu, Okpola BC. An appraisal of the management of ectopic pregnancy in a Nigerian Tertiary Hospital. Ann Med Health Science Res. 2013; 3(2): 166-170.

3. Udigwe GO, Umeononihu OS, MbachuII. Ectopic pregnancy: A 5 year review of cases at Nnemdi Azikiwe Univerisity Teaching Hospital (NAUTH) Nnewi. Niger Med J. 2010; 51:160-3.

4. Bouyer J, Coste J, Shojaei T, Jean-Luc P, Fernandez H, Gerband L, Job-Spira N. Risk Factors for Ectopic Pregnancy: A Comprehensive Analysis Based on a Large Case-Control, Population-based Study in France. Am J. Epidemiol. 2003; 157 (3): 185-194.

5. Maifa Abdulaziz Al-Turki, ISRN Obstetrics and Gynaecology Vol 2013 (2013), http//dx.doi.org/10.1155/2013/97251. 
6. Hamura NN, Bolnga JW, Wangnapi R, Horse AW, Rogerson SJ, Unger HW. The impact of tubal ectopic pregnancy in Papua New Guinea - a retrospective case review. 2013. http//www.biomedcentral.com/1471-2393/13/86.

7. Rashmi A Gaddagi and AP Chandrashekhar, A clinical study of ectopic pregnancy. Journal of clinical and Diagnostic Research. 2012, 6(5): 867-869.

8. De Muylder X: Ectopic pregnancy in Ziwbabwe. Int.J Gynaecol. 1991, 35 (1):55-60.

9. Amoko DH, Buga GA. Clinical Presentation of ectopic pregnancy in Transkei, South Africa. East Africa. Med J. 1995, 72 (12): 770-773

10. V.L Holt, J.R Daling, L.F Voigt et al. Induced abortion and the risk of subsequent ectopic pregnancy. American Journal of public health. 1989. 79(9); 1234-1238.

11. Comprehensive Gynaecology, $3^{\text {rd }}$ edition, Missouri, St. Louis: Mosby 1997; 432.

12. Peterson HB, Xca Z, Hughes J H, Wilcon LS, Tylor LR, Trussel J. The risk of ectopic pregnancy after tubal sterilization. N Engl J Med. 1997; 336: 762-7.

13. Nwanodi O, Khulpateea N. The preoperative diagnosis of primary ovarian pregnancy. Natl Med Asso. 2006, 98(5); 796-8

14. Anorlu RI, Oluwole A, Abudu OO, Adebajo S. Risk factors for ectopic pregnancies in Lagos, Nigeria. Acta Obstet Gynaecol Scand. 2005; 25; 596-8.

15. Edmonds K, editor. Dewherst's Textbook of Obstetrics and gynaecology. $7^{\text {th }}$ ed. Oxford. London: Blackwell science ; 207. Pp 106-16

16. Orji EO, Fasubaa OB, Adeyemi B, Dare FO, Onwardegwu U, Ogunniyi SO. Mortality and morbidity associated with misdiagnosis of ectopic pregnancy in defined Nigerian population. $J$ Obstet Gynacol. 2002; 22: 548-50.

17. Bag TS, Saha DP, Dasgupta N, Sarkar M, Mandal SK, Mondal T, Saha SK. Time Trends in ectopic pregnancy over a decade- a retrospective hospital based study. J Indian Med Assoc. 2012, 109 (10): 727-729.

18. Ghararo EP, Igbafe AA. Ectopic pregnancy revisited in Benin city, Nigeria: analysis of 152 cases. Acta Obstet Gynecol Scand. 2002, 81(12) 1139 - 1143.

19. Stovall TG, Ling Fw, Gray LX. Single dose methotrexate for treatment of ectopic pregnancy. Obstet Gyanecol. 1991; 77(5): 754-7.

20. Menon S, Colinis J. Barnhart KT. Establishing a human chronic gonadotrophic cut off to guide Methotrexate treatment of ectopic pregnancy a systematic review. Fertilsteril. 2007; 87(3): 481-4.

21. Ikme AC, Ezegwki HU. Morbidity and mortality following tubal ectopic pregnancy Enugu Nigeria. $J$ Obstet Gynecol. 2005; 25:596-8.

22. Aboyeyi AP, Fawole AA, Ijaiya Ma, Trends in Ectopic Pregnancy in Ilorin, Nigeria. Nigerian J Surg Res. 2002; 4:611.

23. Gazvani MR. Modern management of Ectopic pregnancy. Br. J Hosp Med. 1996. 56: 597- 9 . 